\title{
Change in body mass index among girls with precocious puberty under treatment
}

Jessie N. Zurita Cruz, M.D. ${ }^{b}$, Irene Díaz Rodríguez, M.D. ${ }^{a}$, Elisa NishimuraMeguro, M.D. ${ }^{a}$, Miguel Á. VillasisKeever, M.D. ${ }^{b}$, Aleida De Jesús Rivera Hernández, M.D. ${ }^{a}$ and Eulalia Garrido Magaña, M.D. ${ }^{a}$

\begin{abstract}
Introduction: Changes in body mass index (BMI) among girls with idiopathic central precocious puberty (ICPP) under treatment have been controversial in other populations. Objective: To assess changes in BMI Z score and the rate of overweight and obesity in Mexican girls with ICPP during their first year of treatment.

Methodology: A retrospective study was conducted among girls with ICPP under treatment with leuprolide, with a somatometry performed every six months, over a 1-year period. An analysis of variance (ANOVA) was done to establish differences in BMI Z score and a multivariate analysis was used to assess the relationship among the different factors.

Results: Among 121 girls, BMI Z score increased from 0.87 to 1.32 , and the rate of overweight and obesity increased from $40.5 \%$ to $70.3 \%$, a statistically significant difference.

Conclusions: Changes in BMIZscore and the rate of overweight and obesity among Mexican girls with ICPP increased significantly.

Key words: central precocious puberty, body mass index, obesity, leuprolide.
\end{abstract}

http:/ /dx.doi.org/10.5546/aap.2016.eng.143

\section{INTRODUCTION}

Central precocious puberty $(\mathrm{CPP})$ is defined as attainment of secondary sexual characteristics before the age of 9 years in boys and 8 years in girls mediated by the early activation of the hypothalamic-pituitary-gonadal axis. ${ }^{1}$

a. Department of Pediatric Endocrinology.

b. Unit for Medical Research in Clinical Epidemiology. High-Specialty Medical Unit (Unidad Médica de Alta Especialidad, UMAE), Children Hospital of Centro Médico Nacional Siglo XXI. Mexican Social Security Institute (Instituto Mexicano del Seguro Social) Mexico.

E-mail address:

Jessie N. Zurita Cruz, M.D.: zuritajn@hotmail.com

Funding: None.

Conflict of interest: None.

Received: 8-9-2015

Accepted: 11-11-2015
The first-line treatment for CPP consists in long-acting gonadotropin-releasing hormone (GnRH) analogs that act by suppressing puberty during the first three months of treatment in most cases. ${ }^{2,3}$ Adverse events are uncommon and include a disproportionate increase in body mass index $(\mathrm{BMI})^{4-8}$ at the expense of fat tissue, and the resulting cardiovascular risk. The mechanism by which these patients are prone to overweight or obesity is unknown, and findings from different series have been inconsistent. ${ }^{9,10}$

In Mexico, overweight among schoolchildren and adolescents is a public health problem and reflects the eating and physical activity habits in a population with a greater genetic risk. The objective of this study was to assess change in BMI Z score ( $\triangle \mathrm{BMIZs})$ and the presence of overweight and obesity in Mexican girls with idiopathic central precocious puberty (ICPP) during their first year of treatment.

\section{PATIENTS, MATERIAL AND METHODS}

A retrospective cohort including Mexican girls diagnosed with ICPP who were under continuous treatment with leuprolide at a dose of $3.75 \mathrm{mg}$ once a month during 12 months was established. Patients with an associated disease or receiving drugs that may have potentially had some effect on weight gain or appetite increase (genetic syndromes, steroid use, fluoxetine, insulin sensitizers, anorexiants or inhibitors of intestinal lipid absorption) were excluded.

The following clinical data were collected from medical records: age, weight, height, pubertal stage, bone age, and serum levels of luteinizing hormone (LH), follicle-stimulating hormone (FSH) and estradiol, at the time of diagnosis and at 6 and 12 months. Overweight was defined as a BMI in the $85^{\text {th }}-94^{\text {th }}$ percentile $(P)$, and obesity, as a BMI in or above the $95^{\text {th }}$ percentile.

The protocol was approved by the local ethics and health research committee of the corresponding hospital.

A one-way ANOVA was used to assess the difference in body mass index Z score (BMIZs) 
at the time of diagnosis and at 6 and 12 months. Change ( $\triangle B M I Z s)$ was estimated by subtracting from the BMIZs at 12 months that at the time of diagnosis of ICPP. These data were analyzed together with baseline nutritional status, having one or both parents who were obese, and the extent of biochemical suppression of ICPP (SPSS, version 17.0).

\section{RESULTS}

Out of had some effect147 patients with ICPP seen between 2005 and 2012, 17 were excluded due to a diagnosis of congenital adrenal hyperplasia, 6 due to a central nervous system tumor (4 astrocytoma tumors and 2 hamartomas),

TABLE 1. General characteristics of the 121 patients with idiopathic central precocious puberty at the time of diagnosis

\begin{tabular}{lcc}
\hline Characteristic & & Average (SD) \\
\hline Age (years) & & $6.8(1.29)$ \\
Weight $(\mathrm{kg})$ & $32.5(10.5)$ \\
Height $(\mathrm{cm})$ & $129.5(12.77)$ \\
BMIZs & & $0.86(1.06)$ \\
Bone age (years) & $10.3(2.2)$ \\
\hline Pubertal stage \% (Tanner*) & 2 & 86.8 \\
& 3 & 13.2 \\
\hline Parental obesity* & None & 6.61 \\
& One & 82.64 \\
& Both & 10.74 \\
\hline Chemistry & LH (IU /L) & $4.2(5.4)$ \\
at the time of & FSH (IU /L & $6.5(8.5)$ \\
diagnosis & Estradiol (pg/mL) & $38.6(3.2)$ \\
\hline
\end{tabular}

SD: standard deviation; LH: luteinizing hormone;

FSH: follicle-stimulating hormone;

BMIZs: body mass index Z score. and 3 because they had not received continuous treatment for 12 months. One hundred and twenty-one patients were included; their average age at the time of diagnosis was $6.8 \pm 1.2$ years old. Of them, $86.7 \%(n=105)$ were Tanner stage II, while $13.2 \%(n=16)$, Tanner stage III. Puberty remained clinically and biochemically suppressed in $95 \%$ of patients (Table 1).

In relation to patients' nutritional status at the time of diagnosis, the average BMIZs was $0.86 \pm 1.06,60$ patients $(49.5 \%)$ had a normal nutritional status, 35 (29\%) were overweight, and $26(21.5 \%)$ were obese. By grouping the latter two, 61 patients $(50.4 \%)$ were overweight or obese. $\Delta$ BMIZs was $0.46 \pm 0.66 \mathrm{~kg} / \mathrm{m}^{2}(p=0.001)$, which resulted in an increase in overweight and obesity percentage to $33 \%$ and $37 \%$, respectively (Table 2, Figure 1).

A significant increase in BMIZs was mainly observed in the group with normal weight or overweight. The proportion of girls whose nutritional status changed to overweight and obesity after 12 months of treatment was $46.6 \%$ in the group with an initial BMIZs $<\mathrm{P}_{85}$, and $25 \%$ of patients in the overweight group changed to being obese (Figure 2).

Six patients did not achieve an adequate biochemical suppression of puberty, mainly due to an inconsistent administration of the GnRH analog. In this subgroup, increase in BMIZs was similar to that in the adequately suppressed group ( $\triangle$ BMIZs: $0.74 \pm 0.65$ ), although it was not possible to demonstrate a statistical significance with the baseline status, probably due to the number of cases. A multivariate analysis did not show a difference in $\triangle B M I Z$ s based on LH levels or a history of one or both parents with obesity.

TABLE 2. Nutritional status during follow-up of the 121 patients with idiopathic central precocious puberty

\begin{tabular}{|c|c|c|c|c|}
\hline & & \multicolumn{3}{|c|}{ Average (SD) } \\
\hline & & Baseline & 6 months & 12 months \\
\hline \multicolumn{2}{|c|}{ BMIZs* } & $0.86(1.06)$ & $1.1(0.97)$ & $1.3(0.88)$ \\
\hline \multirow[t]{3}{*}{ Nutritional status** } & Normal & 49.5 & 37 & 29.7 \\
\hline & Overweight & 29 & 33 & 33.1 \\
\hline & Obesity & 21.5 & 30 & 37.2 \\
\hline
\end{tabular}

*ANOVABMIZs: baseline versus at 6 months, $p=0.096$; at 6 months versus at 12 months, $p=0.395$; baseline versus at 12 months, $p=0.001$.

** Percentage.

SD: standard deviation; BMIZs: body mass index Z score. 


\section{DISCUSSION}

Cardiovascular conditions and obesityassociated diseases are the main cause of morbidity and mortality in many countries, including Mexico. An increase in body fat proportion during childhood has been related to an early biological maturation, and even to the presence of precocious puberty.

This may reflect the natural history of these girls given that the factors that condition overweight or obesity in these patients remain present (genetic burden, overeating, sedentary lifestyle). In addition, the suppression of puberty may contribute to an imbalanced calorie intakeexpenditure ratio because, in theory, it reduces the expenditure attributed to longitudinal growth and development of secondary sexual characteristics. ${ }^{10}$

In this retrospective study, in which a specific control of diet or physical activity were not included, it was observed that most overweight or obese girls continued to be overweight or obese, and that $40 \%$ of girls with a previous normal weight developed overweight or obesity. These data indicate a $70 \%$ rate of overweight or obesity at 12 months of treatment versus $50.4 \%$ at treatment initiation. The size of the increase in BMIZs (from 0.86 to $1.3, \Delta$ BMIZs: $0.46 \pm 0.66$ ) is higher than that reported by Boot ${ }^{4}$ (from 0.96 to 1.38, $\triangle$ BMIZs: 0.42 ) in 34 Caucasian girls after two years of treatment and by Aguiar ${ }^{7}$ in 176 Brazilian girls treated with goserelin, although the proportion of cases with overweight or obesity is higher than the $30 \%$ (versus $19 \%$ at the time

FIGURE 1.Progression of body mass index $Z$ score in girls with idiopathic central precocious puberty

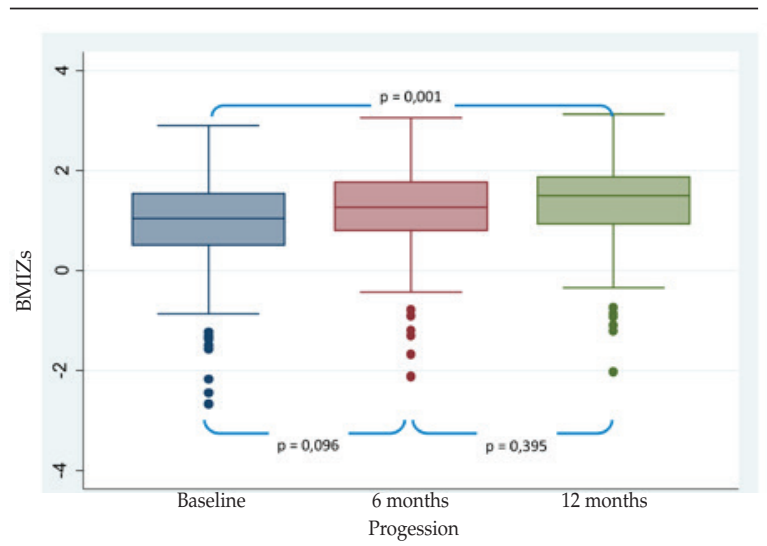

One-way ANOVA, with Bonferroni post hoc analysis. BMIZs: body mass index $\mathrm{Z}$ score. of diagnosis) reported by Palmert et al. ${ }^{5}$ in 96 Caucasians girls.

In addition, in a cohort of 115 Israelite girls ${ }^{8}$ treated with leuprolide during 2-3 years, a high frequency of overweight or obesity was also reported, but no changes in BMIZs were observed. Moreover, a study conducted among 101 Italian girls showed that the BMIZs was significantly reduced during treatment. ${ }^{9}$

None of the studies referenced here clearly stated whether any preventive intervention had been implemented. Such increase in BMIZs may be the result of the specific characteristics of this ethnic group, like the genetic predisposition to cardiometabolic alterations and environmental factors.

The frequency of overweight and obesity in the studied cases by chronological age $(6.8 \pm 1.29$ years) and by biological age (10.6 \pm 1.8 years) was compared to their frequency as reported in Mexican girls by the 2012 National Health Survey. ${ }^{11}$ It is evident that, like in many other populations, the frequency of overweight and obesity among girls with idiopathic central precocious puberty is much higher than that reported for the general population, both by chronological and biological age (40.5\% versus $24.7 \%$ and $38.2 \%$ versus $40.5 \%$, respectively). The increase in BMIZs was even higher than that reported by the normal adiposity rebound that occurs between 5 and 7 years of chronological age, ${ }^{12}$ which is characterized by an approximate increase of $16 \%$ of total body fat or $0.2 \mathrm{BMIZs}$ points.

FIGURE 2.Changes innutritional status over a 12-month follow-up. $N=121$

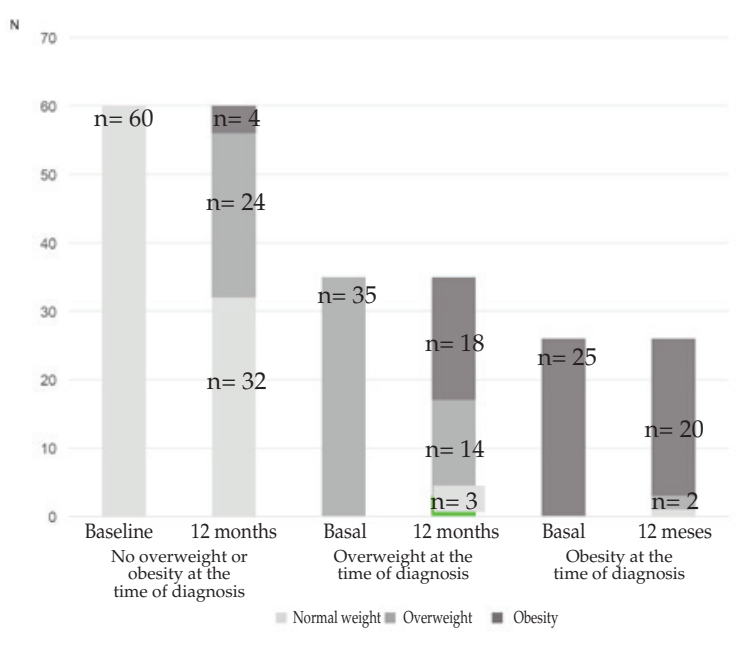


Such disproportionate increase in overweight and obesity, especially among girls with a normal $\mathrm{BMI}$ at the time of diagnosis, suggests that, in addition to inheritance, a sedentary lifestyle and overeating, there may be some other mechanism that contributes to a greater change towards overweight or obesity, at least in the studied population.

Given the retrospective natureof this study, there are no data on other cardiovascular risk factors available (lipid profile, hyperinsulinemia, adipocytokines), which have been reported to increase in girls with central precocious puberty under treatment whose nutritional status changes. ${ }^{13,14}$

In short, a year after treatment initiation, this group of Mexican girls with ICPP had a higher rate of overweight or obesity than what has been reported in other populations. The rate of progression to obesity was also higher, especially in the group with a normal weight at the time of diagnosis, and this suggests that factors that may be attributed to pubertal suppression may have a role in weight gain. It is important to implement, for girls with precocious puberty and a high risk of obesity, like our population, prevention measures especially targeted at identifying and managing risk factors, as part of the comprehensive management of this condition.

\section{REFERENCES}

1. Sorensen K, Mouritsen A, Aksglaede L, Hagen CP, et al. Recent secular trends in pubertal timing: implications for evaluation and diagnosis of precocious puberty. Horm Res Paediatr 2012;77(3):137-45.

2. Fuld K, Chi C, Neely EK. A randomized trial of 1- and 3-month depot leuprolide doses in the treatment of central precocious puberty. J Pediatr 2011;159(6):982-7.

3. Badaru A, Wilson DM, Bachrach LK, Fechner P, et al. Sequential comparisons of one-month and three-month depot leuprolide regimens in central precocious puberty. $J$ Clin Endocrinol Metab 2006;91(5):1862-7.

4. Boot AM, De Muinck Keizer-Schrama S, Pols HA, Kren- ning EP, et al. Bone mineral density and body composition before and during treatment with gonadotropin-releasing hormone agonist in children with central precocious puberty and early puberty. J Clin Endocrinol Metab 1998;83(2):370-3.

5. Palmert MR, Mansfield MJ, Crowley WF Jr, Crigler JF Jr, et al. Is obesity an outcome of gonadotropin-releasing hormone agonist administration? Analysis of growth and body composition in 110 patients with central precocious puberty. J Clin Endocrinol Metab 1999;84(12):4480-8.

6. Pasquino AM, Pucarelli I, Accardo F, Demiraj V, et al. Long-term observation of 87 girls with idiopathic central precocious puberty treated with gonadotropin-releasing hormone analogs: impact on adult height, body mass index, bone mineral content, and reproductive function. I Clin Endocrinol Metab 2008;93(1):190-5.

7. Aguiar AL, Couto-Silva AC, Vicente EJ, Freitas IC, et al. Weight evolution in girls treated for idiopathic central precocious puberty with GnRH analogues. J Pediatr Endocrinol Metab 2006;19(11):1327-34.

8. Lazar L, Padoa A, Phillip M. Growth pattern and final height after cessation of gonadotropin-supressive therapy in girls with central sexual precocity. J Clin Endocrinol Metab 2007;92(9):3483-9.

9. Arrigo T, De Luca F, Antoniazzi F, Galluzzi F, et al. Reduction of baseline body mass index under gonadotropinsuppressive therapy in girls with idiopathic precocious puberty. Eur J Endocrinol 2004;150(4):533-7.

10. Sørensen K, Mourintsen A, Mogensen SS, Aksglaede L, et al. Insulin sensitivity and lipid profiles in girls with central precocious puberty before and during gonadal suppression. J Clin Endocrinol Metab 2010;95(8):3736-44.

11. Gutiérrez JP, Rivera-Dommarco J, Shamah-Levy T, Villalpando-Hernández S, et al. Encuesta Nacional de Salud y Nutrición 2012. Resultados nacionales. Cuernavaca: Instituto Nacional de Salud Pública de México; 2012:149-52. [Accessed on: September 28, 2014]. Available at: http:// ensanut.insp.mx/informes/ENSANUT2012ResultadosNacionales.pdf.

12. Williams S, Davie G, Lam F. Predicting BMI in young adults from childhood data using two approaches to modelling adiposity rebound. Int J Obes Relat Metab Disord 1999;23(4):348-54.

13. Mul D, Fredriks AM, van Buuren S, Oostdijk W, et al. Pubertal development in The Netherlands 1965-1997. Pediatr Res 2001;50(4):479-86.

14. Glueck CJ, Morrison JA, Wang P. Insulin resistance, obesity, hypofibrinolysis, hyperandrogenism, and coronary heart disease risk factors in 25 pre-perimenarchal girls age $<$ or $=14$ years, 13 with precocious puberty, 23 with a first-degree relative with polycystic ovary syndrome. $J$ Pediatr Endocrinol Metab 2008;21(10):973-83. 